\title{
High inter-rater reliability of Japanese bedriddenness ranks and cognitive function scores: a hospital-based prospective observational study
}

Masaki Tago ${ }^{1 *}$, Naoko E. Katsuki ${ }^{1}$, Shizuka Yaita ${ }^{1}$, Eiji Nakatani ${ }^{2,3}$, Shun Yamashita ${ }^{1}$, Yoshimasa Oda ${ }^{4}$ and Shu-ichi Yamashita ${ }^{1}$

\begin{abstract}
Background: The statistical validities of the official Japanese classifications of activities of daily living (ADLs), including bedriddenness ranks (BR) and cognitive function scores (CFS), have yet to be assessed. To this aim, we evaluated the ability of BR and CFS to assess ADLs using inter-rater reliability and criterion-related validity.
\end{abstract}

Methods: New inpatients aged $\geq 75$ years were enrolled in this hospital-based prospective observational study. BR and CFS were assessed once by an attending nurse, and then by a social worker/medical clerk. We evaluated interrater reliability between different professions by calculating the concordance rate, kappa coefficient, Cronbach's a, and intraclass correlation coefficient. We also estimated the relationship of the Barthel Index and Katz Index with the BR and CFS using Spearman's correlation coefficients.

Results: For the 271 patients enrolled, BR at the first assessment revealed 66 normal, 10 of J1, 15 of J2, 18 of A1, 31 of $A 2,37$ of $B 1,35$ of $B 2,22$ of $C 1$, and 32 of $C 2$. The concordance rate between the two BR assessments was $68.6 \%$, with a kappa coefficient of 0.61 , Cronbach's a of 0.91 , and an intraclass correlation coefficient of 0.83 , thus showing good inter-rater reliability. BR was negatively correlated with the Barthel Index $(r=-0.848, p<0.001)$ and Katz Index $(r=-0.820, p<0.001)$, showing justifiable criterion-related validity.

Meanwhile, CFS at the first assessment revealed 92 normal, 47 of 1, 19 of 2a, 30 of 2b, 60 of 3a, 8 of 3b, 8 of 4, and 0 of M. The concordance rate between the two CFS assessments was $70.1 \%$, with a kappa coefficient of 0.62 , Cronbach's a of 0.87 , and an intraclass correlation coefficient 0.78 , thus also showing good inter-rater reliability. CFS was negatively correlated with the Barthel Index $(r=-0.667, p<0.001)$ and Katz Index $(r=-0.661, p<0.001)$, showing justifiable criterion-related validity.

Conclusions: BR and CFS could be reliable and easy-to-use grading scales of ADLs in acute clinical practice or large-scale screening, with high inter-rater reliabilities among different professions and significant correlations with well-established, though complicated to use, instruments to assess ADLs.

(Continued on next page)

\footnotetext{
*Correspondence: tagomas@cc.saga-u.ac.jp

'Department of General Medicine, Saga University Hospital, 5-1-1 Nabeshima, Saga 849-8501, Japan

Full list of author information is available at the end of the article
}

(c) The Author(s). 2021 Open Access This article is licensed under a Creative Commons Attribution 4.0 International License, which permits use, sharing, adaptation, distribution and reproduction in any medium or format, as long as you give appropriate credit to the original author(s) and the source, provide a link to the Creative Commons licence, and indicate if changes were made. The images or other third party material in this article are included in the article's Creative Commons licence, unless indicated otherwise in a credit line to the material. If material is not included in the article's Creative Commons licence and your intended use is not permitted by statutory regulation or exceeds the permitted use, you will need to obtain permission directly from the copyright holder. To view a copy of this licence, visit http://creativecommons.org/licenses/by/4.0/. The Creative Commons Public Domain Dedication waiver (http://creativecommons.org/publicdomain/zero/1.0/) applies to the data made available in this article, unless otherwise stated in a credit line to the data. 
(Continued from previous page)

Trial registration: UMIN000041051 (2020/7/10).

Keywords: Barthel index, Bedriddenness ranks, Cognitive function scores, Concordance rate, Cronbach's a, Interrater reliability, Intraclass correlation coefficient, Kappa coefficient, Katz index, Spearman's correlation test

\section{Background}

In the early 1990s, the Ministry of Health, Labour and Welfare (MHLW) released classifications for activities of daily living (ADLs), consisting of bedriddenness ranks and cognitive function scores [1]. These classifications have been widely used under the Japanese Health Insurance and Nursing-care Insurance systems, by attending physicians of elderly patients to assess them for nursing care insurance eligibility [2], by certified evaluators of long-term care to assess persistent disabilities of patients in their own home, or by attending nurses to determine the level of hospital care or discharge support required by elderly inpatients [3-5]. Bedriddenness ranks assess the degree of bedriddenness, which is classified into nine grades using four classification steps (S1, Fig. A) [5]. Cognitive function scores are used to evaluate cognitive impairment, which is classified into eight grades using five classification steps (S1, Fig. B) [5]. In aged societies with limited medical and nursing care resources, such as Japan, easily obtainable bedriddenness ranks and cognitive function scores could be used as comprehensive ADL indicators to screen at-risk older people for their daily living assistance requirements. Furthermore, bedriddenness ranks and cognitive function scores could be used as common tools between hospital or senior care home settings and home or local community settings of patients. While it would be ideal to gather information about specific basic ADLs of all older patients, many are left unassessed due to the overwhelmingly large number of requirements needed to even qualify for an assessment in Japan, which is globally at the forefront of our aged society. Other developed countries with an aged society will certainly experience the same situation as Japan in the near future. These classifications are already used to evaluate ADLs in older patients in common settings, such as hospitals, nursing-care facilities, and local communities, to provide patients with consecutive, long-term care in Japan.

Other than the MHLW bedriddenness ranks and cognitive function scores, several standard and established scores of ADLs and impairment of cognitive function MHLW have been reported. These include the Barthel Index (BI), which classifies the abilities of 10 basic ADLs into two to four grades [6], the Katz
Index (KI), which classifies six basic ADLs into two grades (an independent or care-requiring condition), and the Mini-Mental State Examination (MMSE), which evaluates 11 items (e.g. naming objects, calculation, and manual dexterity while drawing). The BI, $\mathrm{KI}$, and MMSE are well-established measures; however, they are complex and can be difficult to implement. Indeed, despite their high inter-rater reliability $[7,8]$, they are complicated and time-consuming to perform - particularly the BI and MMSE [9, 10] which makes these measures difficult to use in an acute care hospital setting or to evaluate many subjects, such as mass screening $[3-5,11]$. On the other hand, bedriddenness ranks and cognitive function scores are extremely simple and easy to implement, and could therefore be more suited to such situations $[3-5,11]$. Despite their routine use in daily clinical practice and in research settings in Japan $[3-5,11]$, the precision and validation of bedriddenness ranks and cognitive function scores have yet to be established.

We herein report the usefulness of the MHLW bedriddenness ranks and cognitive function scores as tools to assess ADLs. For this, we examined inter-rater reliability and criterion-related validity in a prospective investigation of inpatients at an acute care hospital in a suburban city in Japan.

\section{Methods \\ Study design and patients}

This study was a hospital-based prospective observational study. The subjects were inpatients aged 75 years or older at Yuaikai Oda Hospital (S2, Appendix.), an acute care hospital in a suburban city in Japan, who were admitted from November 2017 to September 2019. The following patients were excluded: those who did not consent to participate in the study, those whose hospital stay was shorter than $24 \mathrm{~h}$, those who were in a serious or possibly fatal condition, and/or those with miscellaneous conditions that made evaluation impossible. A serious or possibly fatal condition was defined as having a disturbance of consciousness equal to or more severe than III-100 of the Japan Coma Scale within $72 \mathrm{~h}$ of admission, meaning that they were unable to open their eyes or take action to avoid painful stimuli [12], had poor vital signs, with a shock index $>1$ 
(i.e., pulse rate divided by systolic blood pressure $>1$ ) [13], showed percutaneous oxygen saturation $<90 \%$, and required administration of $8 \mathrm{~L} / \mathrm{min}$ or more of oxygen.

\section{Data and data sources}

The variables we checked from the medical records on admission were age, sex (male or female), ambulance transfer (presence or absence), admission with a referral letter from a primary physician (presence or absence), duration of hospitalization (days), department of admission (Internal Medicine, Surgery, Cardiology, Dermatology, Otorhinolaryngology, Neurosurgery), MHLW bedriddenness rank and cognitive function score, emergency admission (presence or absence), place of abode (home, nursing home, or other place), basic ADLs (eating, moving, personal maintenance, going to the toilet, bathing, walking, going up and down the stairs, dressing, defecation, and urination; independently or not), and diseases causing hospitalization (according to the International Classification of Diseases, 10th edition: ICD-10). Furthermore, we calculated the BI and KI using data on basic ADLs that were routinely and systematically assessed in each patient on admission by an attending nurse.

Bedriddenness ranks were classified into five grades, which were further divided into nine grades, as follows: normal, J (J1, J2), A (A1, A2), B (B1, B2), and C $(\mathrm{C} 1, \mathrm{C} 2)$ (S1, Fig. A). Cognitive function scores were classified into six grades, which were further divided into eight grades, as follows: normal, 1, 2 (2a, 2b), 3 (3a, 3b), 4, and M (S1, Fig. B) [5, 14]. In this study, MHLW bedriddenness ranks and cognitive function scores were checked twice; at Oda hospital, bedriddenness ranks and cognitive function scores of all inpatients aged 75 years or older are routinely checked by an attending nurse within $24 \mathrm{~h}$ after admission, which are subsequently confirmed by another nurse in charge of discharge support care, with results recorded in the medical chart both times. The results of this routine check of bedriddenness ranks and cognitive function scores were derived from the medical charts for Assessment 1. For Assessment 2, these results were checked independently within $72 \mathrm{~h}$ after admission by a medical social worker or a medical clerk of the hospital, i.e. a person of a medical profession other than a nurse, who was blinded to the results of Assessment 1. The flowchart shown by in supplemental Figure 1 (S1, Fig.) shows the scoring procedure for both Assessment 1 and 2. Although the criterion of Bedriddenness rank $J$ is "A person who has mild disorders, but who is almost independent in activities of daily living and can go out using public transport (J1) or around the neighborhood (J2)", bedriddenness ranks were evaluated at the patients' bedside in the hospital, for both Assessment 1 and 2 . These evaluations were made according to information obtained during interviews with the patient or family members, or observations about the patient's condition. For Assessment 1, a referral letter or nursing records were also used in these evaluations. All variables other than the results of Assessment 2 were collected from medical charts.

\section{Statistical analysis}

The background characteristics of all the eligible patients were analyzed according to the grade of bedriddenness ranks or cognitive function scores. Categorical background characteristic variables are presented as the numbers of patients and percentages, and continuous background characteristic variables as the median and quartile ranges. Categorical variables were analyzed using the Chi-square test, and continuous variables were analyzed using an analysis of variance and F-test.

After excluding patients with missing data in Assessment 2, the concordance rate, kappa coefficient, Cronbach's $\alpha$, and intraclass correlation coefficient between Assessment 1 and 2 for both the bedriddenness ranks and cognitive function scores were calculated. The correlations of bedriddenness ranks/cognitive function scores with BI and KI were analyzed using Spearman's rank correlation coefficient.

Statistical significance was set at $p<0.05$. IBM SPSS Statistics (version 25, IBM, Armonk, New York, USA) was used for the statistical analyses.

\section{Ethical considerations}

This study conforms to Ethical Guidelines for Medical and Health Research Involving Human Subjects issued by the Japanese MHLW and the Ministry of Education, Culture, Sports, Science, and Technology. This study was approved by the research ethics committee of the Yuai-kai Foundation and Oda Hospital (No. 20171201). We obtained consent from each patient individually, and anonymity of the patients was protected.

\section{Results}

Enrollment and background characteristics of patients

During the study period, 3222 inpatients aged 75 years or older were admitted, 2906 of whom were excluded according to the exclusion criteria. After excluding patients with missing data, 271 patients were eligible to be enrolled (Fig. 1). Table 1 shows the background characteristics of patients. The median age of patients was 86 years, $114(42.1 \%)$ were men, and the majority of 


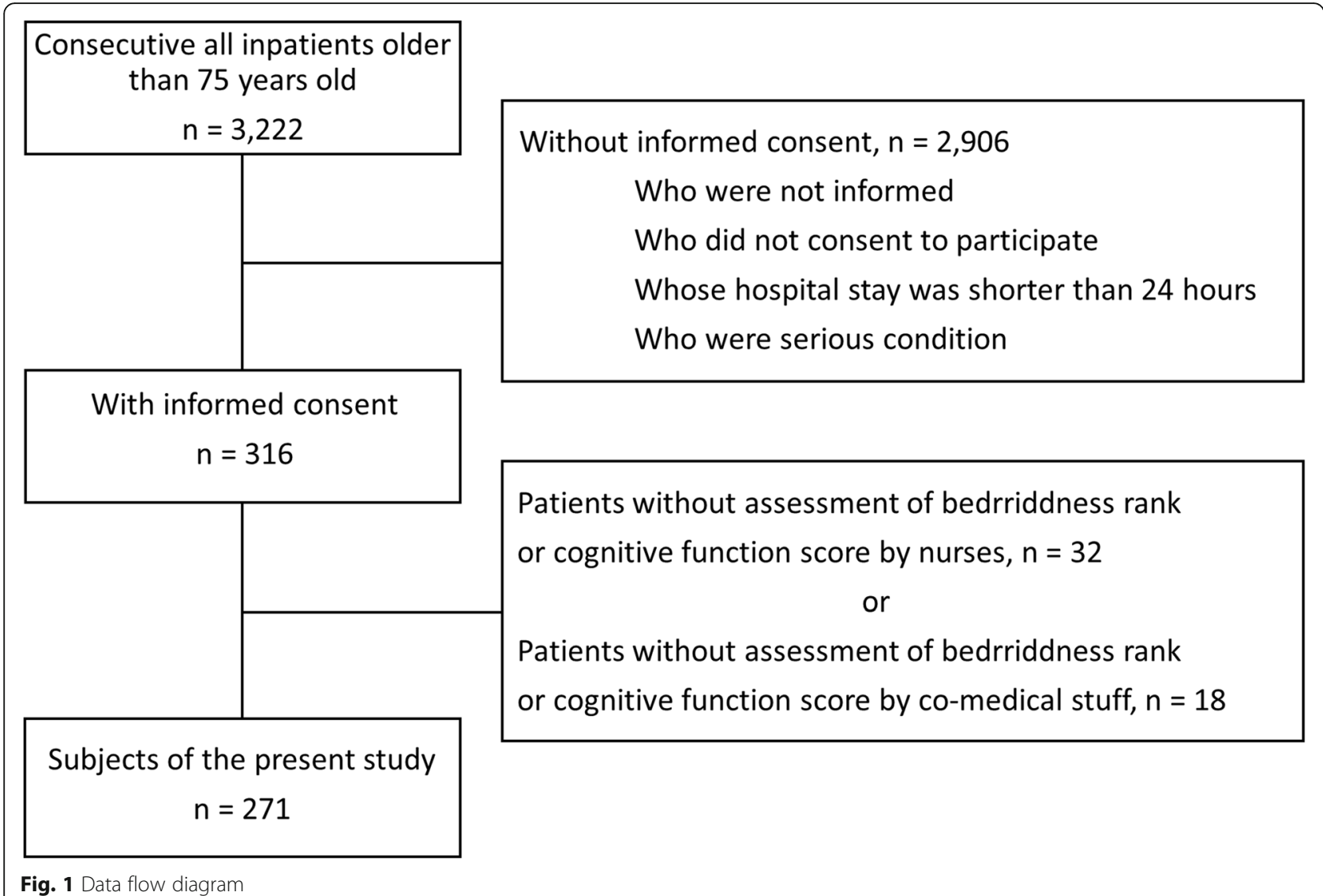

patients $(174 ; 64.2 \%)$ were admitted to the department of Internal Medicine.

Assessment 1 revealed the following: bedriddenness rank frequencies: 66 normal, $10 \mathrm{~J} 1,15 \mathrm{~J} 2,18 \mathrm{~A} 1,31$ $\mathrm{A} 2,37 \mathrm{~B} 1,35 \mathrm{~B} 2,22 \mathrm{C} 2$, and $32 \mathrm{C} 2$; cognitive

Table 1 Characteristics of enrolled patients

\begin{tabular}{lll}
\hline Variables & $\mathbf{n}$ & \% (interquartile) \\
\hline Age (year) & 86 & $(81-90)$ \\
Gender, Male & 114 & 42.1 \\
Admitted by ambulance & 37 & 13.7 \\
Presence of referral medical letter & 107 & 39.5 \\
Length of hospital stay (day) & 13 & $(8-22)$ \\
Department & & \\
Internal medicine & 174 & 64.2 \\
$\quad$ Surgery & 34 & 12.5 \\
$\quad$ Cardiovascular surgery & 33 & 12.2 \\
Dermatology & 14 & 5.2 \\
Plastic surgery & 6 & 2.2 \\
$\quad$ Otolaryngology & 5 & 1.8 \\
$\quad$ Neurosurgery & 5 & 1.8 \\
\hline
\end{tabular}

Categorical variables are presented as the number of patients and percentages, and continuous variables as the median and quartile range function score frequencies: 92 normal, 47 1, 19 2a, 30 2b, 60 3a, 8 3b, 8 4, and $0 \mathrm{M}$. More detailed analyses of background characteristics according to bedriddenness ranks or cognitive function scores showed differences according to age, sex, emergency admission, pre- and post-hospitalization living locations, and duration of hospitalization (Tables 2 and 3). The diseases causing hospitalization consisted of 15 conditions among the major categories, and 144 diseases among the subcategories of the ICD-10. The condition with the highest incidence, 63 cases, among the major categories was cardiovascular diseases, while the disease with the highest incidence, 22 cases, among the subcategories was congestive heart failure.

Inter-rater reliability of the MHLW bedriddenness ranks

The concordance rate of bedriddenness ranks between Assessment 1 and 2 was 68.6\%, kappa coefficient 0.61 , Cronbach's $\alpha$ 0.91, and intraclass correlation coefficient 0.83 (95\% confidence interval (CI): 0.790.86). The concordance rates of Assessment 1 and 2 in each grade of bedriddenness ranks in descending order were $87.5 \%$ for C2, $75.8 \%$ for Normal, $73.0 \%$ for $\mathrm{B} 1,71.0 \%$ for $\mathrm{A} 2,68.2 \%$ for $\mathrm{C} 1,65.7 \%$ for $\mathrm{B} 2$, and less than $50 \%$ for J1, J2, and A1 (Table 4). There was 
Table 2 Characteristics according to bedriddenness rank

\begin{tabular}{|c|c|c|c|c|c|c|c|c|c|c|}
\hline Bedriddenness rank (n) & $\begin{array}{l}\text { Normal } \\
(66)\end{array}$ & J1 (10) & $J 2(15)$ & A1 (18) & A2 (31) & B1 (37) & B2 (35) & C1 (22) & C2 (32) & $p$ value $^{a}$ \\
\hline Age (year) & $82(78-87)$ & $\begin{array}{l}85 \\
(81-91)\end{array}$ & $\begin{array}{l}88 \\
(84-91)\end{array}$ & $\begin{array}{l}82 \\
(80-90)\end{array}$ & $\begin{array}{l}87 \\
(81-90)\end{array}$ & $\begin{array}{l}88 \\
(87-91)\end{array}$ & $\begin{array}{l}89 \\
(82-93)\end{array}$ & $\begin{array}{l}88 \\
(85-93)\end{array}$ & $\begin{array}{l}87 \\
(83-92)\end{array}$ & $<0.001$ \\
\hline Gender, Male & $42(64 \%)$ & $4(40 \%)$ & $1(7 \%)$ & $10(56 \%)$ & $10(32 \%)$ & $12(32 \%)$ & $\begin{array}{l}13 \\
(37 \%)\end{array}$ & $\begin{array}{l}11 \\
(50 \%)\end{array}$ & $9(28 \%)$ & 0.001 \\
\hline Admitted by ambulance & $2(3 \%)$ & $0(0 \%)$ & $1(7 \%)$ & $4(22 \%)$ & $7(23 \%)$ & $3(8 \%)$ & $6(17 \%)$ & $7(32 \%)$ & $6(19 \%)$ & 0.010 \\
\hline Presence of referral medical letter & $15(23 \%)$ & $3(30 \%)$ & $6(40 \%)$ & $8(44 \%)$ & $11(36 \%)$ & $18(49 \%)$ & $\begin{array}{l}14 \\
(40 \%)\end{array}$ & $\begin{array}{l}10 \\
(46 \%)\end{array}$ & $\begin{array}{l}19 \\
(59 \%)\end{array}$ & 0.050 \\
\hline Department: Internal medicine & $34(52 \%)$ & $8(80 \%)$ & $7(47 \%)$ & $11(61 \%)$ & $21(67 \%)$ & $20(54 \%)$ & $\begin{array}{l}28 \\
(80 \%)\end{array}$ & $\begin{array}{l}15 \\
(68 \%)\end{array}$ & $\begin{array}{l}26 \\
(81 \%)\end{array}$ & 0.182 \\
\hline General surgery & $8(12 \%)$ & $1(10 \%)$ & $5(33 \%)$ & $4(22 \%)$ & $4(13 \%)$ & $6(16 \%)$ & $1(3 \%)$ & $2(9 \%)$ & $3(9 \%)$ & - \\
\hline Cardiovascular Surgery & $14(21 \%)$ & $0(0 \%)$ & $1(7 \%)$ & $1(6 \%)$ & $3(10 \%)$ & $7(19 \%)$ & $2(6 \%)$ & $4(18 \%)$ & $1(3 \%)$ & - \\
\hline $\begin{array}{l}\text { Place of abode before admission: } \\
\text { Home }\end{array}$ & $65(99 \%)$ & $9(90 \%)$ & $\begin{array}{l}15 \\
(100 \%)\end{array}$ & $14(78 \%)$ & $27(87 \%)$ & $26(70 \%)$ & $\begin{array}{l}30 \\
(86 \%)\end{array}$ & $\begin{array}{l}18 \\
(82 \%)\end{array}$ & $\begin{array}{l}16 \\
(50 \%)\end{array}$ & $<0.001$ \\
\hline Care facility & $0(0 \%)$ & $1(10 \%)$ & $0(0 \%)$ & $3(17 \%)$ & $3(10 \%)$ & $5(14 \%)$ & $2(6 \%)$ & $1(5 \%)$ & $1(3 \%)$ & - \\
\hline Hospital & $1(2 \%)$ & $0(0 \%)$ & $0(0 \%)$ & $1(6 \%)$ & $1(3 \%)$ & $6(16 \%)$ & $3(9 \%)$ & $3(14 \%)$ & $\begin{array}{l}15 \\
(47 \%)\end{array}$ & - \\
\hline Duration of hospitalization (day) & $9(5-12)$ & $\begin{array}{l}8(5- \\
22)\end{array}$ & $12(3-18)$ & $\begin{array}{l}11(9- \\
17)\end{array}$ & $\begin{array}{l}16(9- \\
25)\end{array}$ & $\begin{array}{l}14(8- \\
22)\end{array}$ & $\begin{array}{l}16 \\
(11-22)\end{array}$ & $\begin{array}{l}12 \\
(7-23)\end{array}$ & $\begin{array}{l}26 \\
(12-40)\end{array}$ & $<0.001$ \\
\hline Place of abode after discharge: Home & $53(95 \%)$ & $5(63 \%)$ & $\begin{array}{l}13 \\
(100 \%)\end{array}$ & $11(65 \%)$ & $21(81 \%)$ & $16(50 \%)$ & $\begin{array}{l}16 \\
(46 \%)\end{array}$ & $7(37 \%)$ & $2(7 \%)$ & $<0.001$ \\
\hline Care facility & $1(2 \%)$ & $1(13 \%)$ & $0(0 \%)$ & $2(12 \%)$ & $3(12 \%)$ & $12(38 \%)$ & $\begin{array}{l}13 \\
(37 \%)\end{array}$ & $6(32 \%)$ & $7(26 \%)$ & - \\
\hline Hospital & $1(2 \%)$ & $1(13 \%)$ & $0(0 \%)$ & $3(18 \%)$ & $1(4 \%)$ & $1(3 \%)$ & $4(11 \%)$ & $2(11 \%)$ & $\begin{array}{l}10 \\
(37 \%)\end{array}$ & - \\
\hline Death within 30 days after discharge & $1(2 \%)$ & $1(14 \%)$ & $0(0 \%)$ & $0(0 \%)$ & $0(0 \%)$ & $2(6 \%)$ & $1(3 \%)$ & $2(12 \%)$ & $4(17 \%)$ & 0.059 \\
\hline
\end{tabular}

Categorical variables are presented as the number of patients and percentages, and continuous variables as the median and quartile range

${ }^{a}$ For continuous and categorical variables, between-group comparisons were made using the F-test for analysis of variance and the Chi-square test, respectively

no significant difference in concordance rates of bedriddenness ranks between Assessment 1 and 2 among the major categories of the ICD-10 (Chi-square test, $X^{2}=11.1, p=0.681$, S3, Table.).

\section{Inter-rater reliability of the MHLW cognitive function scores}

The concordance rate of cognitive function scores between Assessment 1 and 2 was 70.1\%, kappa coefficient 0.62, Cronbach's $\alpha$ 0.87, and intraclass correlation coefficient $0.78 \quad(95 \%$ CI: $0.73-0.82)$. No patients were classified as having a cognitive function score $\mathrm{M}$ in Assessment 1. The concordance rates of Assessment 1 and 2 in each grade of cognitive function scores in descending order were $87.5 \%$ for $3 \mathrm{~b}, 85.9 \%$ for Normal, $75 \%$ for $3 \mathrm{a}, 75 \%$ for 4 , $63.8 \%$ for 1 , and less than $50 \%$ for $2 \mathrm{a}$ and $2 \mathrm{~b}$ (Table 5). There was no significant difference in concordance rates of cognitive function scores between Assessment 1 and 2 among the major categories of the ICD-10 (Chi-square test, $x^{2}=14.5, p=$ $0.415, \mathrm{~S} 3$, Table.).

\section{Criterion-related validity of MHLW bedriddenness ranks and cognitive function scores}

Bedriddenness ranks were significantly correlated with BI $(\mathrm{r}=-0.848, p<0.001$; Fig. 2a) and with $\mathrm{KI}(\mathrm{r}=-$ $0.820, p<0.001$; Fig. 2b). Cognitive function scores were significantly correlated with BI $(\mathrm{r}=-0.667, p<0.001$; Fig. 3a) and with KI ( $r=-0.661, p<0.001$; Fig. $3 \mathrm{~b})$.

\section{Discussion}

A good inter-rater reliability of the MHLW bedriddenness ranks was found in this study. The BI and KI, which are well established scales to assess ADLs, have been reported to have good inter-rater reliabilities, as indicated by a Pearson's correlation coefficient of 0.9 and by an intraclass correlation coefficient of 1.00 [7]. However, the BI takes a long time to implement due to its complexity [10], and the KI is unreliable when examining patients who require assistance for almost all of their basic ADLs [15], both of which are significant disadvantages. In comparison, the simplicity and high reliability of the MHLW bedriddenness ranks could means that this is a better scale to assess ADLs in contexts such as nursing homes or mass screenings, where many elderly patients 
Table 3 Characteristics according to cognitive function score

\begin{tabular}{|c|c|c|c|c|c|c|c|c|c|c|}
\hline Cognitive function score (n) & $\begin{array}{l}\text { Normal } \\
(92)\end{array}$ & $1(47)$ & $2 a(19)$ & $2 b(30)$ & $3 a(60)$ & $3 b(8)$ & $4(8)$ & $M(0)$ & $\begin{array}{l}\text { Unknown } \\
\text { (7) }\end{array}$ & $p$ value $^{a}$ \\
\hline Age (year, median) & $82(78-87)$ & $\begin{array}{l}88 \\
(81-90)\end{array}$ & $\begin{array}{l}90 \\
(83-92)\end{array}$ & $\begin{array}{l}88 \\
(82-92)\end{array}$ & $\begin{array}{l}89 \\
(85-93)\end{array}$ & $\begin{array}{l}88 \\
(86-94)\end{array}$ & $\begin{array}{l}84 \\
(81-89)\end{array}$ & - & $82(-)^{b}$ & $<0.001$ \\
\hline Gender, Male & 47 (51\%) & $22(47 \%)$ & $5(26 \%)$ & $11(37 \%)$ & $\begin{array}{l}19 \\
(32 \%)\end{array}$ & $\begin{array}{l}3 \\
(38 \%)\end{array}$ & $\begin{array}{l}4 \\
(50 \%)\end{array}$ & $\begin{array}{l}0 \\
(0 \%)\end{array}$ & $3(43 \%)$ & 0.272 \\
\hline Admitted by ambulance & $6(7 \%)$ & $10(21 \%)$ & $2(11 \%)$ & $3(10 \%)$ & $\begin{array}{l}10 \\
(17 \%)\end{array}$ & $\begin{array}{l}2 \\
(25 \%)\end{array}$ & $\begin{array}{l}3 \\
(38 \%)\end{array}$ & $\begin{array}{l}0 \\
(0 \%)\end{array}$ & $1(14 \%)$ & 0.101 \\
\hline Presence of referral medical letter & $23(25 \%)$ & $22(47 \%)$ & $7(37 \%)$ & $11(37 \%)$ & $\begin{array}{l}31 \\
(52 \%)\end{array}$ & $\begin{array}{l}5 \\
(63 \%)\end{array}$ & $\begin{array}{l}4 \\
(50 \%)\end{array}$ & $\begin{array}{l}0 \\
(0 \%)\end{array}$ & $4(57 \%)$ & 0.024 \\
\hline Department: Internal medicine & $50(54 \%)$ & $30(64 \%)$ & $\begin{array}{l}15 \\
(79 \%)\end{array}$ & $18(60 \%)$ & $\begin{array}{l}48 \\
(80 \%)\end{array}$ & $\begin{array}{l}5 \\
(63 \%)\end{array}$ & $\begin{array}{l}3 \\
(38 \%)\end{array}$ & $\begin{array}{l}0 \\
(0 \%)\end{array}$ & $5(71 \%)$ & 0.323 \\
\hline General surgery & $15(16 \%)$ & $7(15 \%)$ & $2(11 \%)$ & $2(7 \%)$ & $4(7 \%)$ & $\begin{array}{l}3 \\
(38 \%)\end{array}$ & $\begin{array}{l}1 \\
(13 \%)\end{array}$ & $\begin{array}{l}0 \\
(0 \%)\end{array}$ & $0(0 \%)$ & - \\
\hline Cardiovascular Surgery & $14(15 \%)$ & $7(15 \%)$ & $2(11 \%)$ & $5(17 \%)$ & $3(5 \%)$ & $0(0 \%)$ & $\begin{array}{l}1 \\
(13 \%)\end{array}$ & $\begin{array}{l}0 \\
(0 \%)\end{array}$ & $1(14 \%)$ & - \\
\hline $\begin{array}{l}\text { Place of abode before admission: } \\
\text { Home }\end{array}$ & 85 (92\%) & $42(89 \%)$ & $\begin{array}{l}16 \\
(84 \%)\end{array}$ & 27 (90\%) & $\begin{array}{l}38 \\
(63 \%)\end{array}$ & $\begin{array}{l}4 \\
(50 \%)\end{array}$ & $\begin{array}{l}6 \\
(75 \%)\end{array}$ & $\begin{array}{l}0 \\
(0 \%)\end{array}$ & $4(57 \%)$ & $<0.001$ \\
\hline Care facility & $5(5 \%)$ & $3(6 \%)$ & $1(5 \%)$ & $0(0 \%)$ & $4(7 \%)$ & $\begin{array}{l}2 \\
(25 \%)\end{array}$ & $\begin{array}{l}1 \\
(13 \%)\end{array}$ & $\begin{array}{l}0 \\
(0 \%)\end{array}$ & $0(0 \%)$ & - \\
\hline Hospital & $2(2 \%)$ & $2(4 \%)$ & $2(11 \%)$ & $3(10 \%)$ & $\begin{array}{l}18 \\
(30 \%)\end{array}$ & $\begin{array}{l}2 \\
(25 \%)\end{array}$ & $\begin{array}{l}1 \\
(13 \%)\end{array}$ & $\begin{array}{l}0 \\
(0 \%)\end{array}$ & $3(43 \%)$ & \\
\hline Duration of hospitalization (day) & $10(6-17)$ & $\begin{array}{l}12(7- \\
23)\end{array}$ & $\begin{array}{l}14 \\
(11-27)\end{array}$ & $\begin{array}{l}13(8- \\
20)\end{array}$ & $\begin{array}{l}16 \\
(10-26)\end{array}$ & $\begin{array}{l}16 \\
(11-23)\end{array}$ & $\begin{array}{l}19 \\
(4-39)\end{array}$ & - & $7(-)^{\mathrm{b}}$ & 0.010 \\
\hline Place of abode after discharge: Home & $70(89 \%)$ & $27(66 \%)$ & $9(50 \%)$ & $14(54 \%)$ & $\begin{array}{l}19 \\
(35 \%)\end{array}$ & $\begin{array}{l}2 \\
(29 \%)\end{array}$ & $\begin{array}{l}2 \\
(33 \%)\end{array}$ & $\begin{array}{l}0 \\
(0 \%)\end{array}$ & $2(29 \%)$ & $<0.001$ \\
\hline Care facility & $5(6 \%)$ & $5(12 \%)$ & $4(22 \%)$ & $8(31 \%)$ & $\begin{array}{l}16 \\
(30 \%)\end{array}$ & $\begin{array}{l}4 \\
(57 \%)\end{array}$ & $\begin{array}{l}2 \\
(33 \%)\end{array}$ & $\begin{array}{l}0 \\
(0 \%)\end{array}$ & $3(43 \%)$ & - \\
\hline Hospital & $3(4 \%)$ & $5(12 \%)$ & $2(11 \%)$ & $1(4 \%)$ & $9(17 \%)$ & $\begin{array}{l}1 \\
(14 \%)\end{array}$ & $\begin{array}{l}2 \\
(33 \%)\end{array}$ & $\begin{array}{l}0 \\
(0 \%)\end{array}$ & $1(14 \%)$ & - \\
\hline Death within 30 days after discharge & $1(1 \%)$ & $2(5 \%)$ & $1(6 \%)$ & $0(0 \%)$ & $7(14 \%)$ & $0(0 \%)$ & $0(0 \%)$ & $\begin{array}{l}0 \\
(0 \%)\end{array}$ & $1(14 \%)$ & 0.079 \\
\hline
\end{tabular}

Categorical variables are presented as the number of patients and percentages, and continuous variables as the median and quartile range

${ }^{a}$ For continuous and categorical variables, between-group comparisons were made using the F-test for analysis of variance and the Chi-square test, respectively

${ }^{b}$ This category has no quartile range

require care for daily life, or busy clinical settings such as acute care hospitals. Additionally, bedriddenness ranks could provide us with more detailed information on patients who are bedridden by dividing them into two categories, B (Chair-bound) and C (Bed-bound) [16, 17]. However, we should note that there were relatively lower concordance rates of patients belonging to bedriddenness ranks J1, J2, and A1 between Assessment 1 and 2 than those of patients belonging to other categories. In Assessment 1, which was performed by attending nurses, information was also available from bedside observation of patients or from patients' family members; however, in Assessment 2, which was performed by a medical social worker or medical clerk, the source of information was limited to a brief interview with patients. This highlights the need to gain information not only from patients themselves when using these easy-to-use, reliable scales, but also other sources such as from their family members, especially for patients whose conditions fluctuate according to the day and time of day.

The MHLW cognitive function scores also had an excellent inter-rater reliability, MHLW as indicated by a kappa coefficient of 0.62, Cronbach's $\alpha$ of 0.87 , and intraclass correlation coefficient 0.78. The MMSE [18] and ABC Dementia Scale [19] are existing measures of cognitive function that have been reported to have good inter-rater reliabilities, as shown by a kappa coefficient of 0.98 and weighted kappa coefficient of 0.75 , respectively [7]. However, the MMSE consists of 11 items, including drawing pictures [7], and the $\mathrm{ABC}$ Dementia Scale of 13 items [19], which makes these measures cumbersome to use in extremely busy clinical settings in Japan, such as acute care hospitals or for mass screenings [5]. In contrast, cognitive function scores are simpler and easier-to-use, while also having sufficient reliability for use in mass screening or busy clinical 
Table 4 Differences of bedriddenness rank between assessments by nurses and by other staff

\begin{tabular}{|c|c|c|c|c|c|c|c|c|c|c|c|c|c|}
\hline \multicolumn{2}{|c|}{ Bedriddenness rank } & \multirow[b]{2}{*}{ Normal } & \multicolumn{8}{|c|}{ Assessment 2} & \multicolumn{2}{|c|}{ Total } & \multirow{2}{*}{$\begin{array}{l}\text { Concordance } \\
\text { rate } \\
\%\end{array}$} \\
\hline & & & $\mathrm{J1}$ & $J 2$ & A1 & A2 & B1 & B2 & $\mathrm{C} 1$ & $\mathrm{C2}$ & $\mathrm{n}$ & $\%$ & \\
\hline \multirow[t]{10}{*}{ Assessment 1} & Normal & 50 & 8 & 1 & 2 & 4 & 0 & 1 & 0 & 0 & 66 & 24.4 & 75.8 \\
\hline & J1 & 2 & 3 & 1 & 1 & 2 & 0 & 0 & 0 & 1 & 10 & 3.7 & 30.0 \\
\hline & $J 2$ & 3 & 1 & 6 & 4 & 0 & 0 & 1 & 0 & 0 & 15 & 5.5 & 40.0 \\
\hline & $\mathrm{A} 1$ & 3 & 2 & 1 & 7 & 2 & 1 & 1 & 0 & 1 & 18 & 6.6 & 38.9 \\
\hline & $\mathrm{A} 2$ & 2 & 1 & 3 & 2 & 22 & 0 & 1 & 0 & 0 & 31 & 11.4 & 71.0 \\
\hline & B1 & 3 & 0 & 0 & 1 & 3 & 27 & 2 & 1 & 0 & 37 & 13.7 & 73.0 \\
\hline & B2 & 2 & 1 & 0 & 0 & 5 & 4 & 23 & 0 & 0 & 35 & 12.9 & 65.7 \\
\hline & $\mathrm{C} 1$ & 1 & 1 & 0 & 0 & 2 & 1 & 2 & 15 & 0 & 22 & 8.1 & 68.2 \\
\hline & $C 2$ & 0 & 0 & 0 & 0 & 1 & 1 & 2 & 0 & 28 & 32 & 11.8 & 87.5 \\
\hline & Unknown & 1 & 0 & 0 & 0 & 0 & 0 & 1 & 0 & 3 & 5 & 1.8 & NA \\
\hline \multicolumn{2}{|l|}{ Total } & 67 & 17 & 12 & 17 & 41 & 34 & 34 & 16 & 33 & 271 & 100 & 68.6 \\
\hline
\end{tabular}

The bedriddenness rank, routinely checked by a nurse, was derived from the medical charts for Assessment 1. In Assessment 2, bedriddenness was checked independently within $72 \mathrm{~h}$ after admission, and without knowledge of the Assessment 1 results, by a medical social worker or a medical clerk, i.e. a person of a medical profession other than a nurse

settings, despite their slightly lower inter-rater reliability than the MMSE and ABC Dementia Scale. However, we should also be aware of the relatively lower concordance rates of patients belonging to cognitive function score categories of $2 \mathrm{a}$ and $2 \mathrm{~b}$ between Assessment 1 and 2 than those of patients belonging to other categories, similarly to the case of bedriddenness ranks. Making judgements about whether patients are independent (a cognitive function score 1 or less) or require nursing care (a cognitive function score 3 or more) is straightforward due to the apparentness and unambiguousness of these scores. However, making judgements about patients with a score of 2, who could be somewhat independent under someone's careful observation, despite certain cognitive impairments or difficulties in communication, could rely on subjective assessments, making such judgments less decisive. This characteristic of a cognitive function score of 2 meant that we relied on information gained not only from an interview with patients themselves, but also from interviews with their family members or bedside observations, to better ensure that attending nurses of Assessment 1 made the correct judgment. This also suggests that we should source information not only from patients themselves, but also from their family members or careful bedside observations, for both the cognitive function scores and bedriddenness ranks.

The MHLW bedriddenness ranks can be easier-to-use alternatives to the KI and BI. Furthermore, bedriddenness ranks were correlated with the $\mathrm{BI}$ and $\mathrm{KI}$, which

Table 5 Differences of cognitive function score between assessments by nurses and by other staff

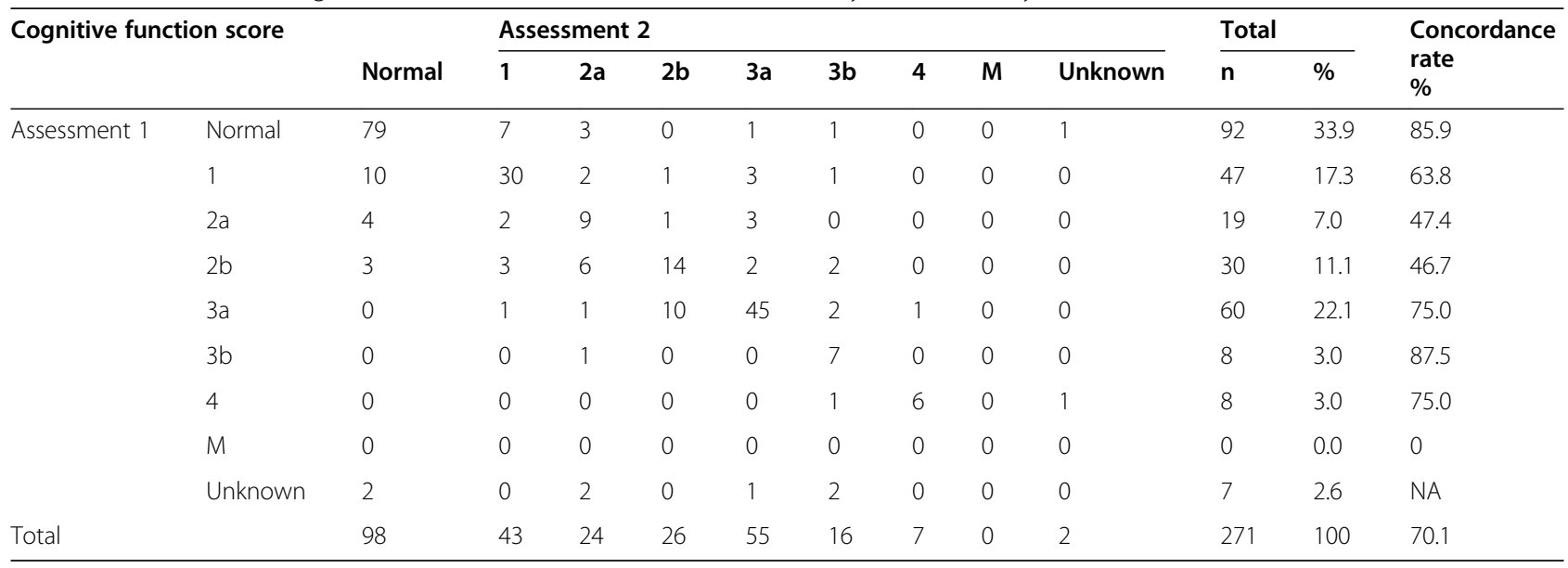

The cognitive function score, routinely checked by a nurse, was derived from the medical charts for Assessment 1 . In Assessment 2 , the cognitive function score was checked independently within $72 \mathrm{~h}$ after admission, without knowing the results of Assessment 1 , by a medical social worker or a medical clerk, i.e. a person of medical profession other than a nurse 

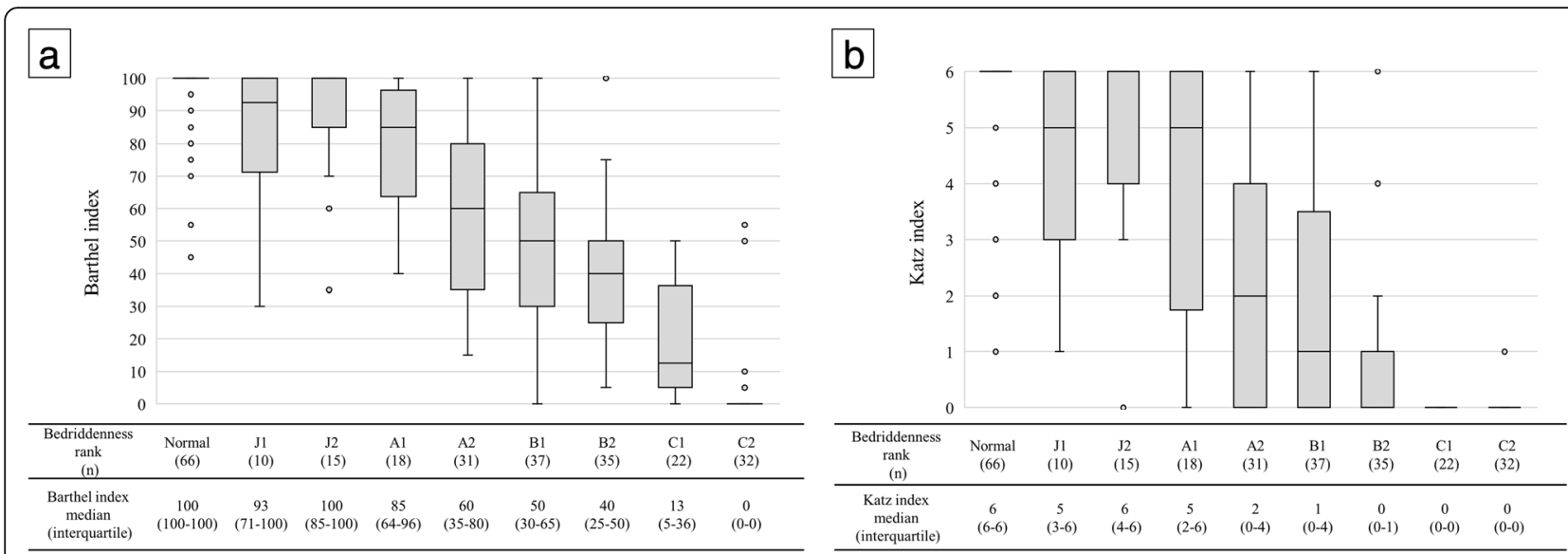

Fig. 2 Box and Whisker diagrams showing the relationship between the MHLW bedriddenness ranks and (a) the BI, and (b) the KI. Spearman's rank correlation coefficient between the MHLW bedriddenness ranks and the BI was $-0.848, p<0.001$ (a), and between the bedriddenness ranks and the $\mathrm{Kl}$ this was $-0.820, p<0.001$ (b)

suggests that the various outcomes related to the BI and KI may also be related to the bedriddenness ranks [2022]. Additionally, low bedriddenness ranks were significantly related to many variables in the present study and pressure ulcers, decreased ADL, malnutrition [3], oral mucosal epithelial detachment [4], and fall-related injuries in the previous studies [5]. We found that bedriddenness ranks, which generally provide a more approximate classification of ADLs than the BI or KI, were correlated with the BI and KI. However, for patients who were almost independent, with a $\mathrm{BI}$ of $\geq 80$ or a $\mathrm{KI}$ of $\geq 5$, the bedriddenness ranks offered a more detailed assessment of ADLs than did the BI or KI by the finer classifications of normal, J1, J2, and A1 (normal to house-bound) (Fig. 2). In a similar way, in completely bedridden patients with a KI of 0 , the bedriddenness ranks gave a more detailed assessment by the finer classifications of $\mathrm{B} 2$ to $\mathrm{C} 2$.
The MHLW cognitive function scores were also significantly correlated with the $\mathrm{BI}$ and $\mathrm{KI}$, and were related to age, sex, and location of livelihood. We did not compare cognitive function scores with other established scales of cognition, such as the MMSE, because not all inpatients completed the assessment of those established scales in this study. Thus, cognitive function scores should be compared with the standard scales of cognitive function in future research.

\section{Limitations}

In the present study, we excluded 2906 patients due to a lack of informed consent after failing to explain the research protocol to patients themselves or their family members within $72 \mathrm{~h}$ after admission. This was partly due to a shortage of human resources, as well as patients' refusal to provide informed consent. However, the
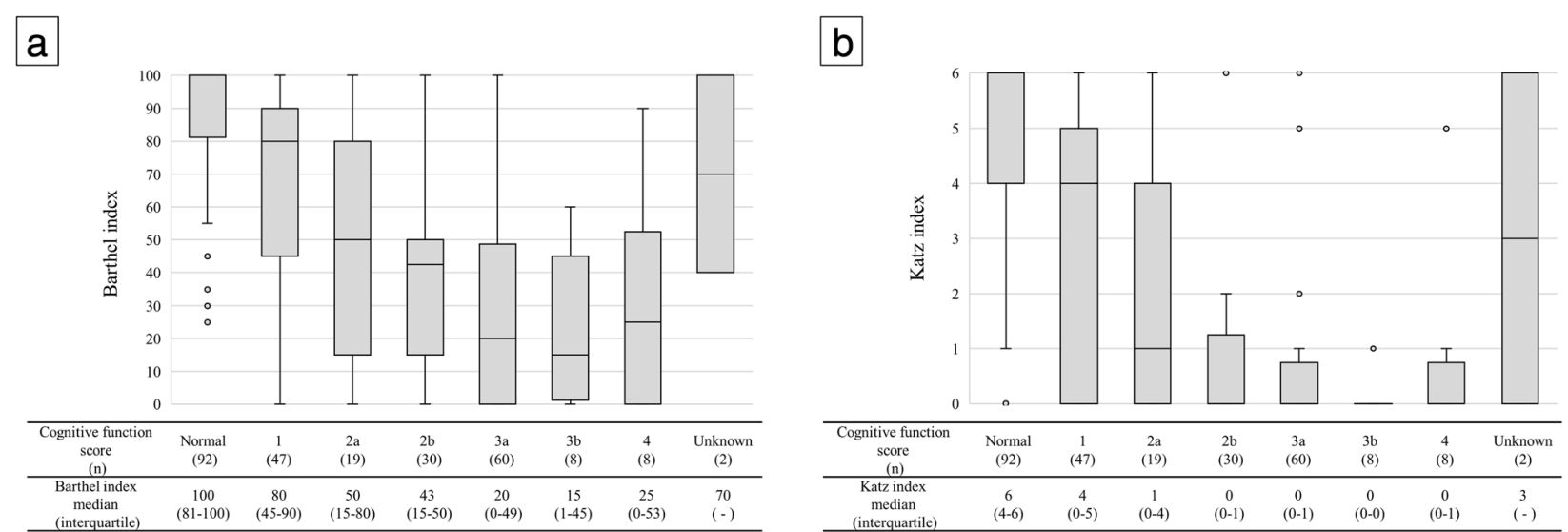

Fig. 3 Box and Whisker diagrams showing the relationship between the MHLW cognitive function scores and (a) the Bl, and (b) the Kl. Spearman's rank correlation coefficient between the MHLW cognitive function scores and the BI was $-0.667, p<0.001$ (a), and between the cognitive function scores and the Kl this was $-0.661, p<0.001$ (b). No patients had a cognitive function score category of $\mathrm{M}$ 
characteristics of included subjects were similar to those of the overall inpatient group (S4, Table), and so we believe that this exclusion had negligible effects on the present results. The MHLW bedriddenness ranks and cognition function scores found in this study were different to those of elderly people living in care facilities [23] and those living in the local community [24]; this could be a result of selection bias, which could have resulted in an inter-rater reliability that differed from other groups of patients with different background characteristics. Furthermore, the concordance rates within each grade of bedriddenness ranks and cognitive function scores varied between Assessments 1 and 2, with low concordance rates, albeit only slightly.

\section{Conclusions}

The MHLW bedriddenness ranks and cognitive function scores are official Japanese classifications of ADLs. Our results indicate that the implementation of these ADL grading scales are more practical than existing ones, especially in busy clinical practice or large-scale screening. Furthermore, they had a high inter-rater reliability, even among assessors with different professions, and their grades were significantly correlated with those of wellestablished scales to assess ADLs.

\section{Abbreviations}

MHLW: Ministry of Health, Labour and Welfare; ADL: Activity of daily living; BI: Barthel Index; KI: Katz Index; MMSE: Mini-Mental State Examination;

Cl: Confidence interval

\section{Supplementary Information}

The online version contains supplementary material available at https://doi. org/10.1186/s12877-021-02108-X.

Additional file 1: S1, Figure. The flowchart used by the assessor for MHLW bedriddenness ranks (A) and cognitive function scores (B).

Additional file 2: S2, Appendix. Characteristics of the Yuai-kai Foundation and Oda Hospital.

Additional file 3: S3, Table. Concordance rates between bedriddenness ranks or cognitive function scores of Assessments 1 and 2 according to the major categories of the International Classification of Diseases, 10th edition.

Additional file 4: S4, Table. Characteristics of all inpatients during the study period.

\section{Acknowledgments}

We thank Fujiko Eguchi, Chieko Nagaike, Kenta Yamaguchi, Osamu Kojiro, and Toshinobu Eguchi from the Yuai-kai Foundation and Oda Hospital for assistance with data acquisition. We thank Masanori Fukushima, MD, PhD, from Translational Research Center for Medical Innovation, for research support and assistance with analysis. We thank Nia Cason, PhD, from Edanz Group (https://en-author-services.edanzgroup.com/ac) for editing a draft of this manuscript.

\section{Authors' contributions}

MT, NEK: Design of the study. Shizuka Y, NEK, Shun Y, YO: Data collection MT, NEK, EN, Shu-ichi Y: Analyses and interpretation of data. All authors contributed to the drafting or revising of the article for important intellectual content and have approved publication of the final version.

\section{Funding}

This work was supported by JSPS KAKENHI Grant Number JP 18 K17322.

\section{Availability of data and materials}

The datasets generated and analyzed in the current study are available in the UMIN-ICDR repository, https://upload.umin.ac.jp/cgi-open-bin/icdr_e/ctr_ view.cgi?recptno=R000046877

\section{Declarations}

Ethics approval and consent to participate

This study conforms to the guidelines for health research involving human subjects issued by the Japanese MHLW and the Ministry of Education, Culture, Sports, Science, and Technology. This study was approved by the research ethics committee of the Yuai-kai Foundation and Oda Hospital (No. 20171201). Informed consent was provided and obtained individually for each patient.

\section{Consent for publication}

Not applicable.

\section{Competing interests}

The authors declare that they have no competing interests.

\section{Author details}

'Department of General Medicine, Saga University Hospital, 5-1-1 Nabeshima, Saga 849-8501, Japan. ${ }^{2}$ Division of Statistical Analysis, Research Support Center, Shizuoka General Hospital, Shizuoka, Japan. ${ }^{3}$ Translational Research Center for Medical Innovation, Foundation for Biomedical Research and Innovation at Kobe, Kobe, Japan. ${ }^{4}$ Department of General Medicine, Yuai-Kai Foundation and Oda Hospital, Kashima, Japan.

Received: 20 November 2020 Accepted: 18 February 2021

Published online: 09 March 2021

\section{References}

1. Sato S, Demura S, Minami M, Kasuga K. Longitudinal assessment of ADL ability of partially dependent elderly people: examining the utility of the index and characteristics of longitudinal change in ADL ability. J Physiol Anthropol Appl Hum Sci. 2002;21:179-87.

2. General Affairs Division, Health and Welfare Bureau For the Elderly Ministry of Health, Labour and Welfare, Japan. The Long-term care Insurance System in: Long-term Care Insurance in Japan. 2002. https://www.mhlw.go.jp/ english/topics/elderly/care/2.html. Accessed 19 Nov 2020.

3. Kosaka K, Yamashita S, Ando C, Endo Y, Taniguchi K, Kikunaga S. Relationships among body mass index, activities of daily living and zinc nutritional status in disabled elderly patients in nursing facilities. J Nutr Sci Vitaminol (Tokyo). 2013;59:420-30.

4. Kawase $Y$, Ogasawara $T$, Kawase $S$, et al. Factors affecting the formation of membranous substances in the palates of elderly persons requiring nursing care. Gerodontology. 2014;31:184-93.

5. Aihara H, Tago M, Oishi T, Katsuki NE, S-i Y. Visual impairment, partially dependent ADL and extremely old age could be predictors for severe fall injuries in acute care settings. Int J gerontol. 2018:12:175-9.

6. Fi M, Dw B. Functional evaluation: the Barthel index. Md State Med J. 1965; 14:5.

7. Hartig MT, Engle VF, Graney MJ. Accuracy of nurse aides' functional health assessments of nursing home residents. J Gerontol A Biol Sci Med Sci. 1997; 52:M142.

8. O'Connor DW, Pollitt PA, Hyde JB, Fellows JL, Miller ND, Brook CP, Reiss BB. The reliability and validity of the mini-mental state in a British community survey. J Psychiatr Res. 1989;23:87-96.

9. Aggarwal A, Kean E. Comparison of the Folstein mini mental state examination (MMSE) to the Montreal cognitive assessment (MoCA) as a cognitive screening tool in an inpatient rehabilitation setting. Neurosci Med. 2010;1:39. 
10. Galeoto G, Lauta A, Palumbo A, Castiglia S, Mollica R, Santilli V, Sacchetti M. The Barthel index: Italian translation, adaptation and validation. Int J Neurol Neurother. 2015;2:2378-3001.

11. Momosaki R, Kakuda W, Yamada N, Abo M. Impact of board-certificated physiatrists on rehabilitation outcomes in elderly patients after hip fracture: an observational study using the J apan R ehabilitation D atabase. Geriatr Gerontol Int. 2016;16:963-8.

12. Ohta T, Waga S, Handa W, et al. New grading of level of disordered consiousness (author's transl). No Shinkei Geka. 1974;2:623-7.

13. Allgöwer M, Burri C. Shock index. Dtsch Med Wochenschr. 1967;92:1947-50.

14. Director General of the Health and Welfare Bureau for the Elderly MoHaW. Criteria for Evaluating the Degree of Independence of Disabled or Cognitive Elderly Persons in Performing Activities of Daily Living. 1991. https://www. mhlw.go.jp/topics/kaigo/kentou/15kourei/sankou4.html. Accessed 19 Nov 2020.

15. Katz S, Ford AB, Moskowitz RW, Jackson BA, Jaffe MW. Studies of illness in the aged: the index of ADL: a standardized measure of biological and psychosocial function. JAMA. 1963;185:914-9.

16. Kok L, Berden C, Sadiraj K. Costs and benefits of home care for the elderly versus residential care: a comparison using propensity scores. Eur J Health Econ. 2015;16:119-31.

17. Naomi A, Shiroiwa T, Fukuda T, Murashima S. Institutional care versus home care for the elderly in a rural area: cost comparison in rural Japan. Rural Remote Health. 2012;12:1817.

18. Folstein MF, Folstein SE, McHugh PR. "Mini-mental state". A practical method for grading the cognitive state of patients for the clinician. J Psychiatr Res. 1975;12:189-98.

19. Umeda-Kameyama Y, Mori T, Wada-Isoe K, et al. Development of a novel convenient Alzheimer's disease assessment scale, the ABC dementia scale, using item response theory. Geriatr Gerontol Int. 2019;19:18-23.

20. Sato S, Demura S, Kobayashi H, Nagasawa Y. The relationship and its change with aging between ADL and daily life satisfaction characteristics in independent Japanese elderly living at home. J Physiol Anthropol Appl Hum Sci. 2002;21:195-204.

21. Ahrenfeldt $\mathrm{L}$, Möller S, Thinggaard M, Christensen K, Lindahl-Jacobsen R. Sex differences in comorbidity and frailty in Europe. Int J Public Health. 2019;64:1025-36.

22. Corneliusson L, Sköldunger A, Sjögren K, et al. Residing in sheltered housing versus ageing in place-population characteristics, health status and social participation. Health Soc Care Community. 2019;27:e313-e22.

23. Onishi C, Yuasa K, Sei M, Ewis AA, Nakano T, Munakata H, Nakahori Y. Determinants of life satisfaction among Japanese elderly women attending health care and welfare service facilities. J Med Investig. 2010;57:69-80.

24. Sato S, Demura S, Goshi F, Minami M, Kobayashi H, Nagasawa Y. Utility of ADL index for partially dependent older people: discriminating the functional level of an older population. J Physiol Anthropol Appl Hum Sci. 2001;20:321-6

\section{Publisher's Note}

Springer Nature remains neutral with regard to jurisdictional claims in published maps and institutional affiliations.

Ready to submit your research? Choose BMC and benefit from:

- fast, convenient online submission

- thorough peer review by experienced researchers in your field

- rapid publication on acceptance

- support for research data, including large and complex data types

- gold Open Access which fosters wider collaboration and increased citations

- maximum visibility for your research: over $100 \mathrm{M}$ website views per year

At BMC, research is always in progress.

Learn more biomedcentral.com/submissions 